\title{
Revised web impact factor analysis of Timor Leste University website during COVID-19 pandemic
}

\author{
Tenia Wahyuningrum ${ }^{1}$, Condro Kartiko², Ariq Cahya Wardhana ${ }^{3}$, Teotino Gomes Soares ${ }^{4}$ \\ ${ }^{1}$ Department of Informatics, Institut Teknologi Telkom Purwokerto, Indonesia \\ ${ }^{2,3}$ Department of Software Engineering, Institut Teknologi Telkom Purwokerto, Indonesia \\ ${ }^{4}$ Department of Computer Sciences, Dili Institut of Technology, Timor Leste
}

\begin{tabular}{l} 
Article Info \\
\hline Article history: \\
Received Nov 5, 2020 \\
Revised Mar 2, 2021 \\
Accepted Apr 25, 2021 \\
\hline
\end{tabular}

\section{Keywords:}

Backlink analysis

Revised web impact factor

Timor Leste University

Webometrics

Website quality

\begin{abstract}
The global coronavirus disease 2019 (COVID-19) pandemic requires the Timor Leste government to make a school from home policy. This policy has encouraged several universities to improve the quality of their distance learning services. However, it seems that the government has not gone deep enough to conduct a preliminary study on each university website's readiness to face this. Based on previous research, the university website impact factor is one of the criteria for increasing webometrics rankings. Still, it is not explained in detail the types of referring pages and domains that can affect webometrics rankings. This research investigates the extent to which R-WIF affects webometrics and examines the factors that can improve the university website's quality. We surveyed the revised web impact factor (R-WIF) at seven universities in Timor Leste to determine their academic sites' relative standing. The results show, although some universities have increased the number of backlinks, the webometrics university ranking prefers backlinks that come from high-authorization sites such as .edu and .gov. The correlation value indicates this phenomenon between R-WIF and Webometrics of 0.464 , which means moderate. Universities in Timor Leste need to implement several strategies to improve Webometrics rankings, especially visibility.
\end{abstract}

This is an open access article under the CC BY-SA license.

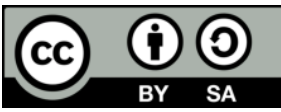

\section{Corresponding Author:}

Tenia Wahyuningrum Department of Informatics Institut Teknologi Telkom Purwokerto

Jl. DI Panjaitan 128 Purwokerto, Digital Convergence Building, 53147, Indonesia

Email: tenia@ittelkom-pwt.ac.id

\section{INTRODUCTION}

Since World Health Organization (WHO) declared coronavirus disease 2019 (COVID-19) a global pandemic [1], all countries have felt the impact, including Timor Leste. The Timor Leste government decided to close all access both from within and outside the country [2]. The deadly virus COVID-19 has affected every aspect of life, business and small traders, and school and university students in Timor Leste. The virus is so poisonous that it requires people to use a mask, living health, and keep their distance [3]. The concept of distance education adopted by the Timor Leste government is called the school at home or "Escola Ba Uma" [4], [5]. This situation forces teachers and students to do social distancing so that they do online learning. The online learning model is considered the best way to channel access to education because it is cheap and flexible [6]. Students are not burdened with transportation, accommodation costs and can determine the most appropriate study time according to the circumstances. Online learning is commonplace in many parts of the world, but universities in Timor Leste are not. Many students reside in an unsupportive environment and a low family economy [7]. Although teachers and students with various limitations rely on themselves to 
access the internet because there is no free WIFI on campus, the internet available in Timor Leste is 25 times slower than other countries in Asia and the Pacific [7]. The Timor Leste government must conduct a university readiness study to face obstacles in implementing online learning to compete with other countries in the world. Among them are seeing the readiness of the university website.

The university website is a new way for all stakeholders (students, lecturers, and the wider community) to communicate. Whether in draft form or through the review process, scientific papers can be shared immediately [8]. Therefore, university websites' quality is essential to work on, one of which is by monitoring webometric rankings. Webometrics is a web-based study on four indicators; visibility, presence, openness, and excellence [9]-[11]. Among the four criteria, visibility is the criterion with the largest percentage-webometrics measures visibility criteria based on web content impact sourced from Ahrefs and Majestic [12]. Based on these circumstances, we surveyed revised web impact factors (R-WIF) at seven universities in Timor Leste to determine their academic sites' relative standing. The high impact factor has a positive correlation to the perception of the reputation of the university website [13]. The R-WIF is a part of WIF that quantitative tool for ranking, assessing, classifying, comparing websites, top-level domains, and subdomains based on the number of links coming into a site from another site in links (as known as a backlink) [8]. In this study, our contribution is to investigate the extent to which R-WIF affects webometric. We also examine the factors that can improve the university website's quality to provide an overview of the university in taking strategic steps. The paper is structured as follows. Section 2 discusses the related work; Section 3 presents the research method. Section 4 and 5 then describes the result and discussion also recommendation. Section 6 presents conclusions and suggests some areas for further investigation.

\section{RELATED WORK}

Research on webometrics as university rank has been carried out by many researchers [14]-[17]. Webometrics uses four assessment criteria, visibility (50\%), presence (5\%), openness (10\%), excellence $(35 \%)$. The most significant percentage of visibility encourages researchers to determine what factors influence it [18]. Several backlinks are considered to increase the visibility, and website impact factors are the most highlighted things. Some of the analytic tools used to calculate the impact factor include Google, ahrefs, majestic SEO to calculate the impact factor [19]. Research by [20] states that citation analysis and link analysis do not have the same analogy, while the number of backlinks has a significant relationship with English-language pages. Their opinion [20] was corroborated by [17], which states that website quality improvement is carried out by introducing one website to get more links. Research by [17] explained that providing services to international visitors can improve a website's ranking. Another study on impact factors conducted by [21] shows that university websites have a moderate influence on the Yahoo! search engine compared to Google. Thus, [21] argues that the number of web pages indexed by Yahoo! is closer to the numbers in the webometrics study. In this analysis, R-WIF, the ratio between the number of links (external backlinks) and the number of web pages published on the website indexed by search engines (not all website pages), is entered into the account. Furthermore, according to [22], increasing the university's rank needs to develop a particular strategy in promoting university websites. We then explored a study [21] to see the extent of the correlation between R-WIF and webometric ranking. We also took a closer look at what kind of link sites webometric prefers to increase its ranking. This study provides solutions and recommendations for improving university rankings as described [22].

\section{RESEARCH METHOD}

The research method consists of four steps: 1) determining the websites, 2) collecting the number of backlinks and number of pages, 3) analyzing the result of data, 4) recommendation. We illustrate the research method as a flowchart of study activities in Figure 1. In the first step, we selected an analytic tool to use in the study. This research is limited to universities with official websites in Timor Leste and focuses on analysis and increased visibility. This paper is analytical research that collects data on impact factors on university websites and analyzes findings to provide conclusions and recommendations. To measure web impact factors, we use the same gauge as cyber metrics Labs to see the development of website backlinks, namely Ahrefs. Ahrefs is a well-known tool for backlinks, and it provides comprehensive information on all backlinks obtained from various third-party referral sites. The advantage of Ahrefs compared to other backlink checking tools is the availability of link data using its crawler such as Googlebot. The websites consist of seven Timor Leste university websites. Their URL address were Universidade Nacional Timor Lorosa'e (UNTL-www.untl.edu.tl/), Dili Institute of Technology (DIT-www.dit.edu.tl/), Institute of Business IOB Timor Leste (IOB-www.iob-tl.com/), Instituto Profissional de Canossa (IPDC-www.ipdc.edu.tl/), Instituto Superior Cristal (ISC-www.isc-tl.com/), Universidade Dili (UNDIL-www.undil.tl/) and Tetun Dili Institute of Technology (TETUNDIT-www.tetundit.tl/). TETUNDIT is not a university or institute in Timor 
Leste. Still, it is languages center unit in DIT. Webometrics considers TETUNDIT to be a different institution from DIT due to the use of a different domain name.

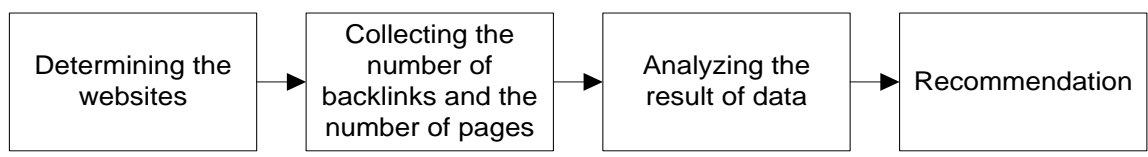

Figure 1. The research method of analyzing R-WIF

We took the backlinks and the number of website pages from March 1, 2020, to September 18, 2020, using Ahrefs tools. We collect data about the number of web pages under a particular website through the Google search engine, using keywords site: URL website (ex. site: untl.edu.tl/). It can calculate the Web Impact Factor, Self Web Impact Factor (S-WIF), and Revised Web Impact Factor (R-WIF) as (1), (2), and (3) [17].

$$
\begin{aligned}
& W I F=\frac{A}{D} \\
& S-W I F=\frac{C}{D} \\
& R-W I F=\frac{B}{D}
\end{aligned}
$$

$A$ is total links to a website (all backlinks and self-link pages), $B$ is a complete backlink to the website (this is a component of A). The $C$ notation represents the number of self-links and navigational links within the same website. The $D$ notation means the number of web pages published on the website indexed by the search engine, not all web pages available on the website. The data collected, then analyzed, includes the number of new and missing backlinks, the number of referring domains, and the number of referring pages. We examine the role of backlinks in increasing impact factors relates to a webometric ranking-the analysis results used to provide recommendations.

\section{RESULTS AND DISCUSSION}

We observed seven website URLs for universities in Timor Leste with a .com or .tl country domain. In the best practices of webometric ranking, the naming of URLs is considered very important. Each institution must choose a unique field, and it is advisable to describe a city, state, or another item. A domain from a free blog provider is considered not to show the universities credibility. Managers must avoid changing the domain name, as they can cause confusion and negatively impact visibility points. Nowadays, hosting rental services are very easy and cheap; universities can overcome technical, political, and economic reasons by using a foreign web service provider.

\subsection{Backlink analysis}

At the beginning of the pandemic (March to April), UNTL, IOB, ISC received an increase in the number of new backlinks by an average of 9,219, and 159. This phenomenon is different from four other websites that experienced a decrease in the number of new backlinks. The DIT has decreased drastically by approximately 139 points. This situation did not last long; slowly but surely, the downward trend in the number of new backlinks continued until July. From August to September, the growth rate for the number of new backlinks to universities in Timor Leste began to move up. Figure 2 represents the new backlink based on seven university websites.

The growth of universities backlinks slowing down, and the loss of backlink in July during the pandemic is the highest one. The most significant number lost of backlinks from July to August is TETUNDIT, as many as 661 and 668 points. The trend that was almost the same in all universities in June was the lowest backlink loss rate. Figure 3 shows the number of backlinks lost during March-September.

Based on Figure 4, almost all universities have increased the total number of unique domains linking to the university's website. IPDC changed backlink numbers in July. Previously, there were no reports that there were backlinks from unique domains; the value was always 0 . The increase in the number of referring domains correlated quite well with the amount of search traffic that the university web page received. The 
"Eskola ba Uma" policy has made students always have to update information about university developments, thereby increasing the number of referring domains.

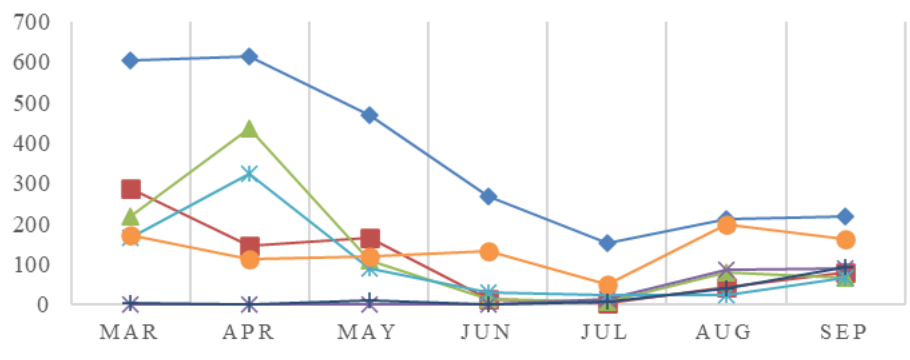

$\longrightarrow$ UNTL $\because-\mathrm{DIT} \longrightarrow \mathrm{IOB} \rightarrow$ * IPDC $\rightarrow$ ISC $\multimap$ TETUNDIT $\longrightarrow$ UNDI

Figure 2. New backlink during March-September

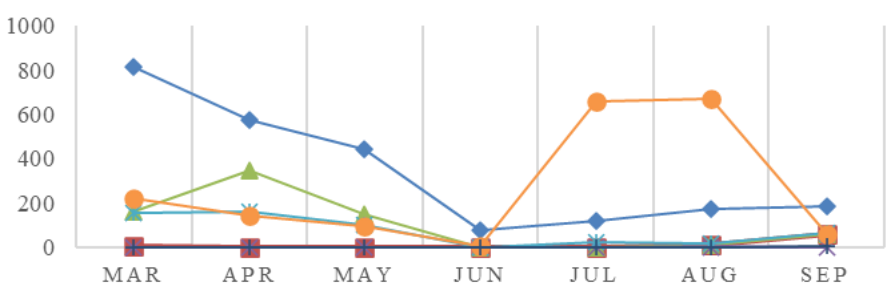

$\rightarrow$ UNIL - DIT $\leadsto$ IOB $\longrightarrow$ IPDC $\rightleftarrows$ ISC $\rightarrow$ TETUNDIT $\longrightarrow$ UNDII

Figure 3. Lost backlink during March-September

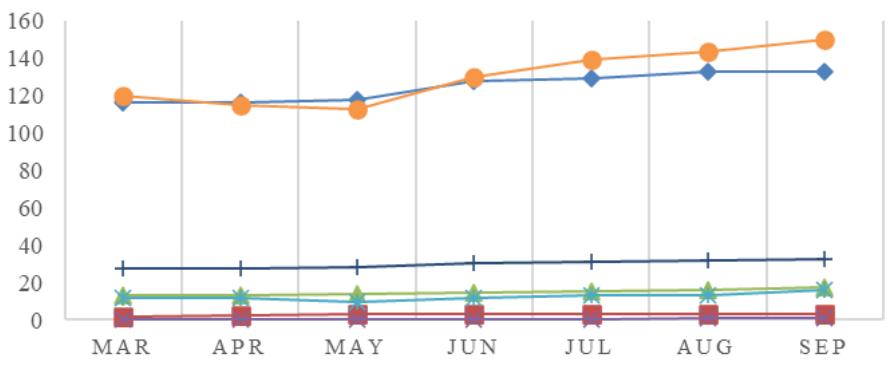

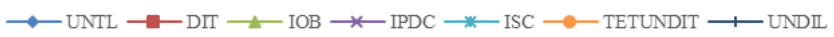

Figure 4. Number of referring domain during March-September

Figure 5 illustrates that almost all university sites have an increase in the referring page. But, TETUNDIT experienced the largest decrease in the number of pages (URLs) pointing to sites among other universities in August and September. IPDC experienced a significant increase in August by 53 referring pages; previously, March, April, May, June, July, were always worth 0. IPDC has changed the site URL, increasing the number of new domain links and pages appearing after August and September. Ahrefs reports that the 301redirect code on IPDC web pages is a technique for changing URLs or website addresses without losing the old domain rankings. 


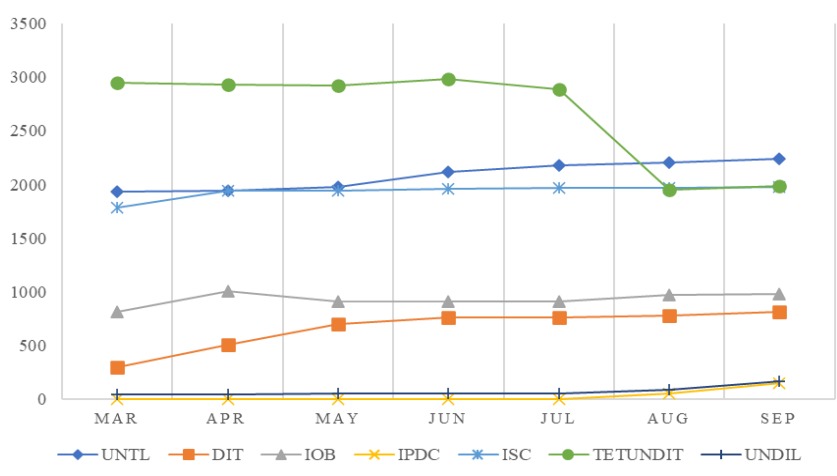

Figure 5. Number of referring pages during March-September

\subsection{Revised web impact factor analysis and the correlation of webometrics}

Based on Table 1, we can see that UNTL has the largest number of backlinks among six other universities, and the largest number of indexed pages is ISC. The R-WIF has been calculated based on (3), the result TETUNDIT has the highest impact factor value. The best-ranking based on R-WIF is TETUNDIT $>$ DIT $>$ UNTL $>$ IOB $>$ UNDIL $>$ IPDC $>$ ISC.

Table 1. R-WIF of seven university websites

\begin{tabular}{ccccc}
\hline University & Backlink & Page indexed & R-WIF & R-Web Impact Factor Rank \\
\hline UNTL & 4010 & 3970000 & 0.0010100756 & 3 \\
DIT & 81 & 31100 & 0.0026045016 & 2 \\
IOB & 989 & 1840000 & 0.0005375000 & 4 \\
IPDC & 186 & 4580000 & 0.0000406114 & 6 \\
ISC & 1974 & 109000000 & 0.0000181101 & 7 \\
TETUNDIT & 2172 & 249000 & 0.0087228916 & 1 \\
UNDIL & 199 & 2300000 & 0.0000865217 & 5 \\
\hline
\end{tabular}

Table 2 shows the ranking of websites based on R-WIF, Webo (August), and Webo (January). In early 2020, IPDC and UNDIL have not entered the webometrics ranking. In the following six months, the two universities entered the webometrics ranking. The number of backlinks and index of existing IPDC pages increased in July. The increase in the number of backlinks increases the impact factor on both websites. The rankings shown differ in the January and August versions of the webometrics and the R-WIF ranking. The highest R-WIF rating is TETUNDIT, while the webometrics version is UNTL.

Table 2. R-WIF of seven university websites

\begin{tabular}{cccc}
\hline University & R-Web Impact Factor Rank & Webometrics Rank (Aug 2020) & Webometrics Rank (Jan 2020) \\
\hline UNTL & 3 & 1 & 1 \\
DIT & 2 & 6 & 5 \\
IOB & 4 & 4 & 3 \\
IPDC & 6 & 7 & - \\
ISC & 7 & 5 & 4 \\
TETUNDIT & 1 & 2 & 2 \\
UNDIL & 5 & 3 & - \\
\hline
\end{tabular}

We then investigated the relationship between webometrics ranking in August (latest release) and RWIF using Spearman correlation. The correlation test step is to see the differences in the two classification methods. Rank similarity testing is carried out with the statistical package for social sciences (SPSS) software by calculating the Spearman rank correlation coefficient. The Spearman rank correlation coefficient $\rho$ on (4).

$$
\rho=1-\frac{6 \sum_{i=1}^{n} d_{i}^{2}}{n\left(n^{2}-1\right)}
$$


Where $d_{i}$ is the difference in rankings for each object $I, i=\in\{1,2, \ldots, n\}$. Table 3 shows the correlation between webometrics and R-WIF ranking using the Spearman correlation formula. The results show that the correlation coefficient is 0.464 or moderate and positive. The significance value (Sig. 2-tailed) is $0.294>$ 0.05, which means a less significant relationship between R-WIF and Webometric rank. This fact is similar to the measurement conducted by [23] at 15 universities in Sri Lanka with Yahoo! R-WIF and Webometrics rank with a correlation value of 0.447 . Therefore, the continuous investigation is needed to reveal further facts.

Table 3. Spearman's rank correlations

\begin{tabular}{|c|c|c|c|c|}
\hline \multicolumn{3}{|c|}{ Correlations } & \multicolumn{2}{|c|}{ R-WIF R-WEBO } \\
\hline \multirow{6}{*}{ Spearman's rho } & & Correlation Coefficient & 1.000 & 0.464 \\
\hline & R-WIF & Sig. (2-tailed) & 0.000 & 0.294 \\
\hline & & $\mathrm{N}$ & 7 & 7 \\
\hline & & Correlation Coefficient & 0.464 & 1.000 \\
\hline & WEBO & Sig. (2-tailed) & 0.294 & 0.000 \\
\hline & & $\mathrm{N}$ & 7 & 7 \\
\hline
\end{tabular}

The backlink investigation then looks at the number of referred domains and the number of backlinks from websites with .edu and .gov domains. This type of domain is often called a Top Level Domain (TLD), which is the domain directly below the root (the dot behind the domain name). The TLD doesn't show domains by country so that anyone can register. The Google algorithm gives more importance to the .edu and .gov domains as they are considered high quality and authority site links. Google counts those backlinks specifically. Ahrefs can indicate the number of unique governmental and educational domains number of links pointing to the target. These include .gov or .edu TLDs and domains that we consider to be governmental or educational. Table 4 shows that the greater the number of referred domains and backlinks from .edu and .gov, the higher the webometrics ranking. UNTL has the most backlinks and referred domains from .edu compared to six other university websites.

Tabel 4. Backlink analysis of .gov and .edu domains

\begin{tabular}{ccccc}
\hline & $\begin{array}{c}\text { Ahrefs.com-Government } \\
\text { referred domain }\end{array}$ & $\begin{array}{c}\text { Ahrefs.com-Educational } \\
\text { referred domain }\end{array}$ & $\begin{array}{c}\text { Ahrefs.com-Government } \\
\text { backlink }\end{array}$ & $\begin{array}{c}\text { Ahrefs.com-Educational } \\
\text { Backlink }\end{array}$ \\
\hline UNTL & 1 & 27 & 3 & 1528 \\
TETUNDIT & 0 & 4 & 0 & 757 \\
IOB & 0 & 2 & 0 & 881 \\
ISC & 0 & 1 & 0 & 807 \\
DIT & 0 & 1 & 0 & 791 \\
UNDIL & 0 & 2 & 0 & 53 \\
IPDC & 0 & 1 & 0 & 0 \\
\hline
\end{tabular}

\section{RECOMMENDATION}

Webometrics considerations in ranking academic websites include paying attention to impact factors. During a pandemic, online teaching and learning activities can increase the impact factor of university websites. This moment is essential to increase the visibility factor of higher education rankings. There are several strategies to increase Timor Leste universities impact.

a. URL naming is very important, each university must choose a unique domain name that signifies its distinctiveness. Each unit within the university is required to use a sub-domain that is based on its main domain. The inclusion of the main and sub-domains needs to be arranged in such a way that events on DIT and TETUNDIT need not occur.

b. Visibility is closely related to popularity, so the university should be expanding the traffic to the main website [24]. One of the ways to generate more traffic is increasing partnering links with other organizations. We recommend collaborations with educational institutions and the government to strengthen backlinks from .edu and .gov. The google algorithm chooses backlinks from trusted sites, so the links you get are more natural. The extension domain .edu and .gov sites are trusted as sites with high credibility because they come from real institutions.

c. Universities should be encouraging all stakeholders involved to increase backlinks by posting educational content from students and lecturers. Students and lecturers can expand the learning activities through a virtual learning environment (e-learning) open to the public. They can use their blog or social media by their own account or the official site on Facebook, Linkedin, Youtube, or Twitter. 
d. The method that can be used to improve learning during a pandemic is project-based learning. Students living in the same area form small study groups to work on projects, experiments, and innovations while adhering to health protocols. Another method is to learn to use local government radio to overcome internet access difficulties. All online and offline learning activities are reported on the official website and social media to increase the impact.

e. Strategies to increase traffic are placing links in web directories, publishing university information through advertisements, virtual and physical, and adding search engine local listings. The number of unique incoming links from other sites indicates the level of recognition of the community's organization level [25]; therefore, to increase the number, it is necessary to determine traffic success and search ranking, also displayed in Google, Yahoo, and Bing site explorer.

f. Universities must take regular measurements using web analytics such as Google webmaster tools, Alexa, Ahrefs, and Majestic to see the progress of the impact they have. By conducting regular analyses, universities can see where they are and determine what criteria need to be improved. We describe the research roadmap regarding increasing visibility or impact in the concept mapping as Figure 6.

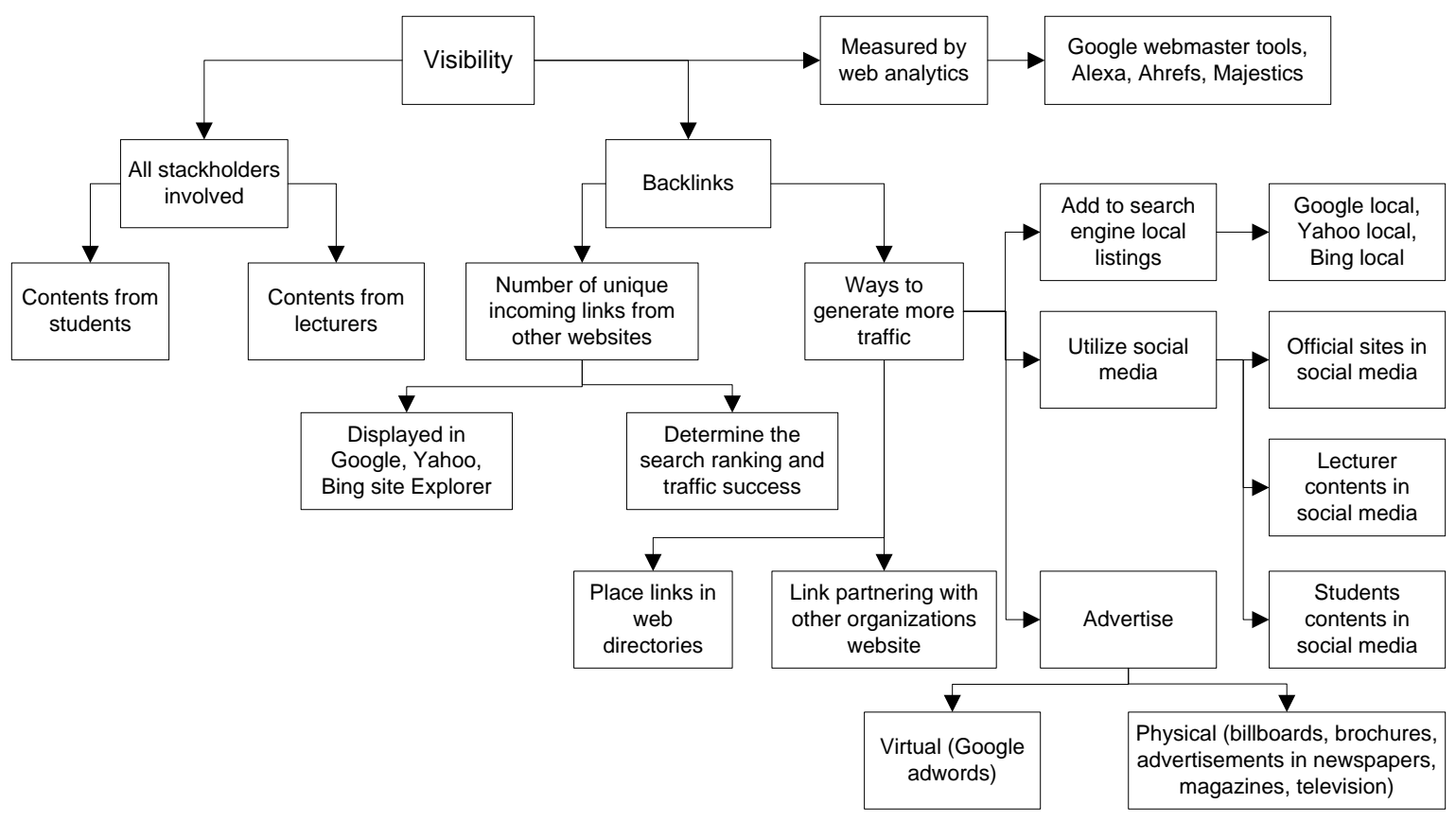

Figure 6. Visibility concept map

\section{CONCLUSION AND FUTURE WORK}

During the COVID-19 pandemic, the school from home policy caused several universities to increase the number of new backlinks. But in general, the growth of backlinks fell during July. From August to September, the number of new backlinks to the University of Timor Leste slowly began to increase. However, almost all universities have experienced an increase in referring pages and unique domain linking. The increase in backlinks and the number of pages indexed by search engines raise university websites' impact factor. Nevertheless, based on the calculation, the correlation between webometrics and R-WIF rankings is 0.464 or moderate and optimistic. The R-WIF of a website is a qualitative indicator that helps measure a website's visibility through its various types of links. It saw the backlinks visibility criteria, but Google prefers sites with high authority, such as backlinks from sites with the edu and .gov domains. Several strategies need to be done by universities in Timor Leste to increase visibility. Increasing visibility can positively impact, namely by providing the broadest possible access to education and recognizing quality globally. This research is the first step for future work; In the future, we will improve investigations into the aspects of presence, openness, and excellence for universities in Timor Leste. We will examine strategies to improve the four aspects based on the priority and importance of each activity. 


\section{ACKNOWLEDGEMENTS}

This research was supported by an LPPM research grant from the Institut Teknologi Telkom Purwokerto for Tenia Wahyuningrum (No. IT Tel1764/LPPM-000/Ka. LPPM/VII/2020)

\section{REFERENCES}

[1] C. Sohrabi et al., "World Health Organization declares global emergency : A review of the 2019 novel coronavirus ( COVID-19)," Int. J. Surg., vol. 76, no. February, pp. 71-76, 2020.

[2] GardaWorld, "Timor-Leste:Entry restrictions imposed for non-nationals as of February 8 amid coronavirus outbreak," GardaWorld, 2020. https://www.garda.com/crisis24/news-alerts/312641/timor-leste-entry-restrictionsimposed-for-non-nationals-as-of-february-8-amid-coronavirus-outbreak (accessed Sep. 16, 2020).

[3] C. M. Toquero, "Challenges and Opportunities for Higher Education amid the COVID-19 Pandemic: The Philippine Context," Pedagog. Res., vol. 5, no. 4, pp. 1-5, 2020.

[4] UNDP, "Socio-Economic Impact Assessment of COVID-19 in Timor-Leste," Dili, 2020. https://www.undp.org > undp > library > covid19 (accessed Sep. 16, 2020).

[5] S. Barnes, T. Hall, B. Kebi, Q. Mok, and L. Palmer, "How Timor-Leste has mobilised against COVID-19," PURSUIT, University of Melbourne, 2020. https://pursuit.unimelb.edu.au/articles/how-timor-leste-has-mobilisedagainst-covid-19(accessed Sep. 16, 2020).

[6] H. Yulia, "Online Learning to Prevent the Spread of Pandemic Corona Virus in Indonesia," English Teach. J., vol. 11, no. 1, pp. 48-56, 2020.

[7] C. Li-li, "Reflecting Online/Distance Learning in Higher Education under COVID-19," Shapesea, 2020. https://shapesea.com/op-ed/covid-19/reflecting-online-distance-learning-in-higher-education-under-covid-19bitter-lessons-from-timor-leste/ (accessed Sep. 16, 2020).

[8] P. Mukhopadhyay, "Measuring Web Impact Factors : A Webometric Study based on the Analysis of Hyperlinks," Department of Library and Information Science, pp. 1-12, 2004.

[9] H. Jati and D. D. Dominic, "A New Approach of Indonesian University Webometrics Ranking Using Entropy and PROMETHEE II,” Procedia Computer Science, vol. 124, pp. 444-451, 2017.

[10] I. F. Aguillo, J. L. Ortega, M. Fernández, and A. M. Utrilla, "Indicators for webometrics ranking of open access repositories," Scienciometrics, vol. 82, no. 3, pp. 477-486, 2010.

[11] D. Kosyakov, A. Guskov, and E. Bykhovtsev, "Webometric Analysis of Russian Scientific and Education Web," in International Conference Mathematical and Information Technologies, pp. 196-207, 2016.

[12] I. F. Aguillo, "Methodology Ranking Web of Universities," webometrics, 2020. http://www.webometrics.info/en/Methodology (accessed Sep. 24, 2020).

[13] A. Noruzi, “The Web Impact Factor : A Critical Review,” Electron. Libr., vol. 24, no. 4, pp. 490-500, 2006.

[14] R. Wardoyo and T. Wahyuningrum, "University Website Quality Ranking Using Logarithmic Fuzzy Preference Programming," Int. J. Electr. Comput. Eng., vol. 8, no. 5, pp. 3349-3358, 2018.

[15] N. R. Ghorbani, Y. Fakour, and S. A. Nojoumi, "The Increasing Trend in Global Ranking of Websites of Iranian Medical Universities during January 2012-2015,” Iran J. Public Heal., vol. 46, no. 8, pp. 1095-1103, 2017.

[16] M. K. Verma and K. Brahma, "A webometric analysis of National Libraries 'websites in South Asia," Annals of Library and Information Studies (ALIS), vol. 64, no. 2, June, pp. 116-124, 2017.

[17] M. Gupta and H. Singh, "Webometric Analysis of Centres of Indian Statistical Institute in India," Libr. Philos. Pract., vol. 4009, pp. 1-19, 2020.

[18] M. Joko, U. Haris, and A. K. Fauziyyah, "Web Analysis of 4ICU and Webometrics Based on University Ranking using Web Impact Factor,” J. Adv. Inf. Syst. Technol., vol. 1, no. 1, pp. 21-35, 2019.

[19] T. Wahyuningrum, N. Rokhman, and A. Musdholifah, "Algorithm Comparison Performance in Assessing the Quality of University Websites," 4th International Conference on New Media Studies (CONMEDIA), pp. 19-24, 2017.

[20] A. Shukla and Vanlalfeli, "Webometric Development in Web Impact Factor Studies : A Literary Review," J. Adv. Libr. Sci., vol. 1, no. 3, pp. 28-36, 2014

[21] S. T. C. I. Wimaladharma and H. M. U. Manjula Herath, "An analysis of significance of Revised Web Impact Factor for ranking the websites of state universities in Sri Lanka," 2016 IEEE International Conference on Information and Automation for Sustainability: Interoperable Sustainable Smart Systems for Next Generation, ICIAfS 2016, pp. 1-5, 2016.

[22] I. Yakymenko, V. Kazymyr, and S. Lytvyn, "Webometrics ranking analysis and possible ways to improve the position of the university," in 2020 IEEE 11th International Conference on Dependable Systems, Services and Technologies (DESSERT), Kyiv, Ukraine, pp. 422-426, 2020.

[23] S. T. C. I. Wimaladharma and H. M. U. M. Herath, "An Analysis of Significance of Revised Web Impact Factor for ranking the websites of state universities in Sri Lanka," 2016 IEEE International Conference on Information and Automation for Sustainability (ICIAfS), Galle, Sri Lanka, pp. 1-5, 2016.

[24] D. P. S. and P. R. Ioannis C. Drivas, "Improving Website Usability and Traffic Based on Users Perceptions and Suggestions-A User-Centered Digital Marketing Approach," Strategic Innovative Marketing, Springer Proceedings in Business and Economics, pp. 255-265, 2019.

[25] D. V Kosyakov, A. E. Gus, and E. S. Bykhovtsev, "Review Russia' s Academic Institutes as Mirrored by Webometrics," Her. Russ. Acad. Sci., vol. 86, no. 6, pp. 490-499, 2016. 


\section{BIOGRAPHIES OF AUTHORS}

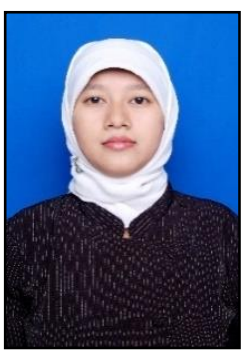

Tenia Wahyuningrum is a lecturer in the Faculty of Informatics at Institut Teknologi Telkom Purwokerto, Indonesia. She took her undergraduate (S.Kom) at STMIK Widya Utama Purwokerto in 2005, and Master (M.T) in the Electrical Engineering Department at Institut Teknologi Bandung in 2010. He earned a Doctoral from the Department of Computer Science, Universitas Gadjah Mada Yogyakarta, Indonesia. Her research areas of interest are HumanComputer Interaction, Software Quality, and Software Engineering. Email: tenia@ittelkompwt.ac.id

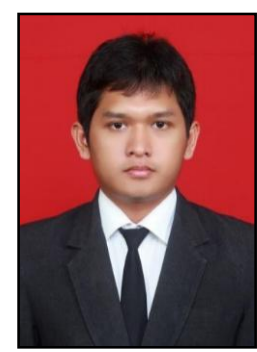

Condro Kartiko is a lecturer at Institut Teknologi Telkom Purwokerto, Indonesia, Department of Software Engineering, Faculty of Informatics. He graduates from Universitas Jenderal Soedirman, majoring in Informatics Engineering as Bachelor's Degree and from Universitas Indonesia, majoring in Information Technology as a Graduate Degree. He was involved in the research and development of social media monitoring and analytics in the industrial field. His publications cover software requirements, software design, software construction, software testing, and software quality. Currently, his research interests range from software engineering and requirements engineering. He is an associate member of IEEE and APTIKOM (Indonesian Association of Higher Education in Informatics and Computing).

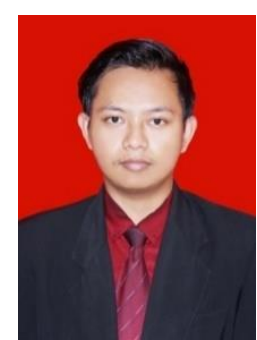

Ariq Cahya Wardhana is a lecturer at Institut Teknologi Telkom Purwokerto, Indonesia, Department of Software Engineering, Faculty of Informatics. He graduates from UIN Syarif Hidayatullah Jakarta, majoring in Informatics Engineering as Bachelor's Degree and from IPB University, majoring in Computer Science as a Graduate Degree. He is an associate member of APTIKOM (Indonesian Association of Higher Eduation in Informatics and Computing). Currently, his research areas of interest are User Experience, Web Technology, Software Engineering, and Digital Business.

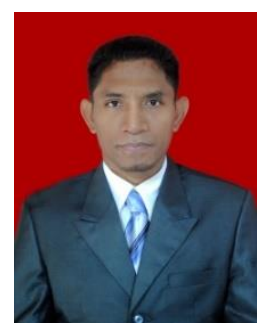

Teotino Gomes Soares is a lecturer in Computer Science Department at Dili Institute of Technology, Timor Leste. He took him undergraduate (B.Sc) at Dili Institute of Technology in 2009, and Master of Computer Science (M.Cs) in Computer Science Department at Universitas Universitas Gadjah Mada in 2015. He is a Doctoral Student at the Department of Computer Science, Universitas Gadjah Mada Yogyakarta, Indonesia. His research areas of interest are Software Engineering, Decision Support System, and Machine Learning. Email: tyosoares@gmail.com 